PROFESIONALES Y HERRAMIENTAS PARA EL DESARROLLO LOCAL Y SUS SINERGIAS TERRITORIALES. EVALUACIÓN Y PROPUESTAS DE FUTURO IX Coloquio Nacional de Desarrollo Local del GTDL-AGE 

ANTONIO MARTÍNEZ PUCHE, XAVIER AMAT MONTESINOS, ISABEL SANCHO CARBONELL y DANIEL SANCHIZ CASTAÑO (EDS.)

\section{PROFESIONALES Y HERRAMIENTAS PARA EL DESARROLLO LOCAL Y SUS SINERGIAS TERRITORIALES. EVALUACIÓN Y PROPUESTAS DE FUTURO}

IX Coloquio Nacional de Desarrollo Local del GTDL-AGE

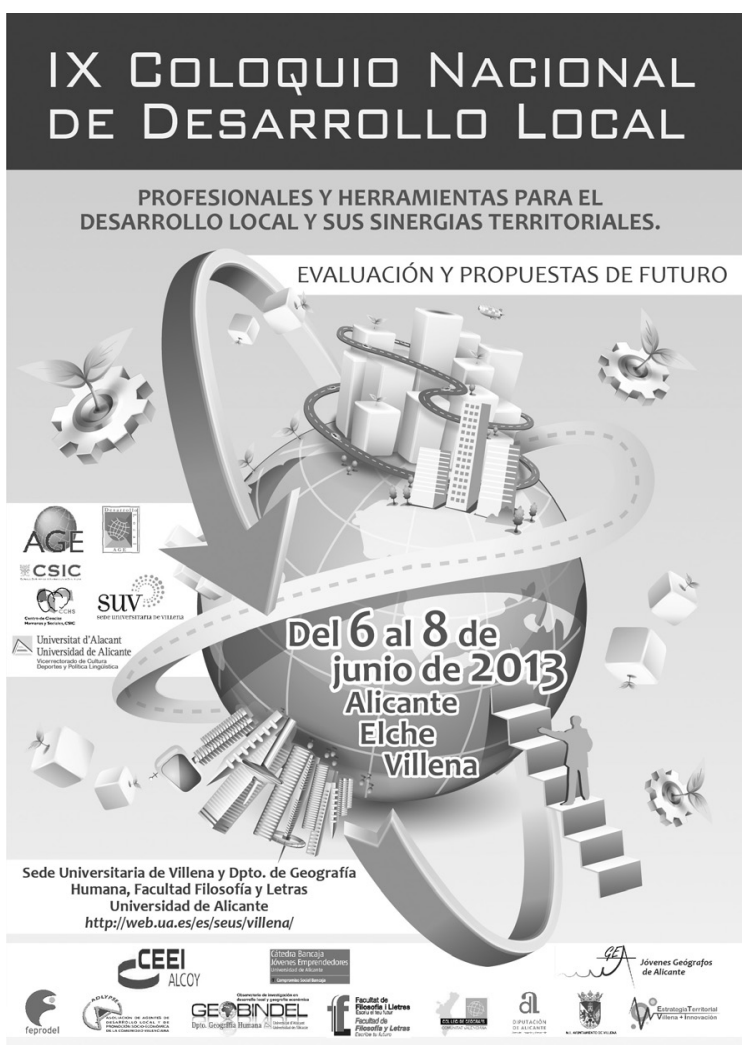


Este libro ha sido examinado y valorado por evaluadores ajenos a la Universidad de Alicante, con el fin de garantizar la calidad científica del mismo.

Publicacions de la Universitat d'Alacant

03690 Sant Vicent del Raspeig

Publicaciones@ua.es

http://publicaciones.ua.es

Telèfon: 965903480

(C) Antonio Martínez Puche, Xavier Amat Montesinos,

Isabel Sancho Carbonell y Daniel Sanchiz Castaño (eds.), 2016

(C) d'aquesta edició: Universitat d'Alacant

ISBN: 978-84-16724-00-0

Dipòsit legal: A 92-2016

Disseny de coberta: candela ink

Composició: Página Maestra (Miguel Ángel Sánchez Hernández)

Impressió i enquadernació: Guada Impresores

\section{unte \\ Unión de Editoriales
Universitarias Españolas \\ WWW.une.es
WWA}

Esta editorial es miembro de la UNE, cosa que garantiza la difusión y comercialización nacional y internacional de sus publicaciones.

Reservados todos los derechos. Cualquier forma de reproducción, distribución, comunicación pública o transformación de esta obra sólo puede ser realizada con la autorización de sus titulares, salvo excepción prevista por la ley. Diríjase a CEDRO (Centro Español de Derechos Repográficos, www.cedro.org) si necesita fotocopias o escanear algún fragmento de esta obra. 


\title{
DEL DESARROLLO A LA RESILIENCIA TERRITORIAL: CLAVES LOCALES PARA LA REACTIVACIÓN ${ }^{1}$
}

\author{
Ricardo Méndez Gutiérrez del Valle \\ Instituto de Economía, Geografía y Demografía \\ Centro de Ciencias Humanas y Sociales CSIC \\ ricardo.mendez@cchs.csic.es
}

\section{RESUMEN}

Son muchos los territorios que se enfrentan hoy al impacto de una crisis económica que es global y sistémica en su dimensión, pero muestra diferentes efectos a escala local que refuerzan las desigualdades espaciales. El emergente concepto de resiliencia territorial pretende explicar por qué algunas áreas son capaces de renovarse y experimentar una revitalización mientras otras permanecen bloqueadas e inician un proceso de declive. El texto plantea el valor de la teoría y de la práctica acumuladas en la promoción del desarrollo local y la creación de ambientes innovadores para comprender mejor la desigual vulnerabilidad de los territorios frente a la actual crisis, la implicación que eso supone para las políticas y, en tal sentido, la propuesta de estrategias para aumentar la resiliencia.

Palabras clave: desarrollo local, innovación territorial, crisis sistémica, vulnerabilidad, resiliencia.

FROM DEVELOPMENT TO TERRITORIAL RESILIENCE: LOCAL KEYS FOR REVITALIZATION

1 La ponencia se integra dentro del proyecto aprobado por el Plan Nacional de $I+D+i$ (Ministerio de Economía y Competitividad) sobre Efectos socioterritoriales de la crisis económica en las áreas urbanas de España: políticas públicas y estrategias de resiliencia (CS02012-36170). 


\section{ABSTRACT}

Many territories are confronted today with the impact of an economic crisis that is global and systemic in its dimension but shows different local consequences emphasizing spatial inequalities. The concept of territorial resilience has recently emerged for explain why some areas manage to renew and revitalise themselves, whereas others remain locked and in decline. This paper claims the value of the theory and practice to promote the local development and innovative environments to understand the keys to unequal vulnerability of territories from the current crisis, the potential implication for policies and, in that sense, proposes strategies to boost resilience.

Key words: local development, territorial innovation, systemic crisis, vulnerability, resilience.

\section{INTRODUCCIÓN}

Suele afirmarse que los tiempos de crisis, que conllevan siempre una ruptura en la trayectoria seguida, son tiempos de cambios profundos e inevitables que exigen una renovación de las ideas y de las formas de actuar establecidas para poder atenuar así sus impactos negativos y recuperar la senda del desarrollo. Por ese motivo, en un contexto como el actual, resulta de especial importancia la capacidad de los territorios para poner en práctica estrategias que aseguren su competitividad y la generación de empleo suficiente y de calidad, mantengan o mejoren la calidad de vida de sus habitantes, promuevan una ordenación territorial más sostenible, o favorezcan una democracia local más participativa. Se trata, en suma, de sustituir prácticas ineficientes o ajenas a los intereses de la mayoría de sus ciudadanos, aportando soluciones nuevas, inclusivas y comprometidas con un objetivo de desarrollo que no se limite al plano económico sino que sea capaz de incorporar las múltiples dimensiones de este concepto (BOISIER, 2013).

Son numerosos los documentos de la Comisión Europea que, desde la Agenda de Lisboa (2000) a la Estrategia Europa 2020, han insistido en la importancia de incrementar la generación, transferencia y aplicación de conocimientos, traducida en diversos tipos de innovaciones, para lograr un desarrollo más "inteligente, sostenible e integrador" (COMISIÓN EUROPEA, 2010). El discurso de la innovación ha pasado así a formar parte de la retórica oficial del desarrollo territorial desde hace dos décadas y se enfrenta ahora al reto de seguir siendo útil para orientar estrategias de revitalización desde los ámbitos locales que hagan frente a la actual crisis económica.

Tal como se afirmaba en la $2^{\mathrm{a}}$ circular del Coloquio, este constituye "una buena oportunidad para, en el contexto actual de cambio y recesión socioeconómica, evaluar y observar, escuchar y debatir sobre lo aportado hasta ahora y 
sobre los retos de futuro en materia de Desarrollo Local". Con esa perspectiva el presente texto, de contenido esencialmente teórico, sigue un itinerario argumental marcado por tres etapas básicas, que se pretenden complementarias entre sí.

En la primera se ha considerado conveniente recordar algunas de las aportaciones conceptuales y teóricas relativas a la dimensión territorial del desarrollo que, surgidas hace ya algún tiempo, han marcado en buena medida la reflexión y la práctica en esta materia y constituyen un recurso interpretativo que necesita hoy de nuevo ser puesto en valor desde la perspectiva del presente. Se destaca así la necesidad de un enfoque multiescalar del desarrollo que, en un mundo que se globaliza, mantenga el significado de lo local en la interpretación de una realidad compleja y plural, así como en la búsqueda de respuestas a los procesos estructurales dominantes en el sistema. También el interés que mantiene el concepto de territorio innovador que, surgido en la geografía económica y dotado por ello de cierto sesgo a favor de la innovación empresarial, se amplió posteriormente al incorporar la noción de innovación social, abordando también la cuestión de las claves necesarias para conseguir una eficaz gobernanza local de la innovación.

En la segunda parte, la ponencia realiza una breve incursión en la dimensión territorial de la actual crisis económica para recordar que los efectos provocados por la misma resultan siempre muy desiguales al afectar en mayor medida a aquellos grupos sociales, empresas y territorios más vulnerables, lo que obliga a revisar dos conceptos emergentes como son los de vulnerabilidad y resiliencia territorial. Sin entrar aquí en un análisis empírico de algunos de sus impactos a escala local, que han sido objeto de mayor atención en otro documento reciente (MÉNDEZ, 2013), aquí se propone un marco interpretativo para, en el tercer apartado, centrar la atención en posibles estrategias para reforzar la resiliencia local, entendida como la capacidad de adaptarse al impacto de un shock de origen externo, renovarse y recuperar el camino del desarrollo. La vinculación que pretende establecerse entre este tipo de estrategias y herramientas con las debatidas durante años para promover el desarrollo local permite alcanzar unas conclusiones finales que, más que resultado de una investigación aún en sus inicios, pretenden ser reflexiones para un debate colectivo sobre la aportación que los profesionales y los teóricos del desarrollo local pueden hacer para enfrentar el escenario actual.

2. LA LÓGICA DEL DESARROLLO Y LA INNOVACIÓN LOCALIZADA: REVISANDO LOS ORÍGENES

Hace ya más de dos décadas los estudios sobre desarrollo vivieron un periodo de profunda renovación como reflejo de las rápidas e intensas transformaciones ocurridas en esos años, tanto en los ámbitos económico y tecnológico como en los de la política, la sociedad o la cultura, acompañadas por una solución 
espacial (HARVEY, 2007) coherente con ese nuevo contexto. El agotamiento del modelo de producción fordista y la incapacidad de las políticas keynesianas para hacer frente a la crisis que estalló en la década de los setenta pusieron en marcha una serie de cambios profundos que son sobradamente conocidos. La consolidación de un modelo productivo más flexible y segmentado apoyado en la revolución digital, una creciente globalización de todo tipo de mercados, cada vez más desregulados por la imposición de una agenda neoliberal, o el reforzamiento de la división espacial del trabajo y del desarrollo geográfico desigual, visible a diferentes escalas, fueron sus principales manifestaciones.

Pero, como contrapunto a un mundo cada vez más dominado por actores y procesos de ámbito global, se hizo también evidente la diversidad de impactos territoriales. Esto vino a revalorizar la necesidad de una perspectiva local para analizar e interpretar mejor la globalización y, más aún, para definir estrategias de respuesta adaptadas a la realidad específica de cada lugar. Pese a su limitada capacidad para enfrentar esas tendencias generales y pese a la evidente dificultad de delimitar lo local en un mundo tejido por relaciones cada vez más densas y con geometrías más complejas (BATHELT et al., 2004), esta forma de abordar los problemas del desarrollo aportó un fundamento teórico común que aún comparten quienes proponen analizar las cuestiones relativas al desarrollo de las sociedades desde una perspectiva territorial explícita y actuar en consecuencia.

Mucho se ha escrito sobre ese conjunto de conceptos y teorías como para volver aquí sobre cuestiones que cuentan con abundante bibliografía. No obstante, sí merece recordarse que tanto desde los estudios sobre desarrollo endógeno y desarrollo local (STÖHR, 1990; VÁZQUEZ BARQUERO, 1999 y 2005), como desde los modelos de innovación territorial (MOULAERT y SEKIA, 2003) -que incluyen la literatura sobre distritos industriales, sistemas productivos locales, clusters, ambientes o milieux innovadores y sistemas regionales de innovación- se establecieron algunos principios comunes que han orientado luego numerosas investigaciones. Aunque la mayoría de esos trabajos buscaron identificar claves para aumentar la capacidad competitiva de las empresas individuales y reforzar las ventajas competitivas del territorio dejando de lado otras dimensiones no económicas del desarrollo, lo que ha provocado frecuentes críticas entre quienes proponen una visión multidimensional del mismo, aquí se limitará la atención a recordar algunas ideas compartidas que conviene revisar a partir de un contexto diferente (PIKE, RODRÍGUEZ POSE y TOMANEY, 2011).

\subsection{La recuperación del actor local como protagonista del desarrollo}

El primer aspecto a recordar es que, sin cuestionar la permanente influencia ejercida por los procesos estructurales inherentes a la lógica del sistema, todas 
estas propuestas vinieron a recordar la importancia de unos actores locales a menudo olvidados en la evolución seguida por cada territorio (GUMUCHIAN et al., 2003). En esa recuperación de los sujetos del desarrollo, mientras los enfoques de raíz económica fijaron su atención en las empresas como actor clave de la competitividad territorial, aquellos otros que proponían una visión más integradora consideraron también la paralela influencia ejercida por los gobiernos de proximidad y la sociedad civil, así como el efecto de sus interacciones en la definición de caminos diferenciados para avanzar en el desarrollo.

En ese sentido, la capacidad de los actores locales para aprovechar su proximidad física, generar sinergias y construir redes de colaboración tejidas por relaciones de confianza -tanto informales como formalizadas- se convirtió en una importante clave explicativa de la diversidad de trayectorias territoriales (PICHIERRI, 2002). Pero frente a visiones excesivamente localistas, atentas tan sólo a las características de las redes locales, las propuestas más atentas a la realidad multiescalar del desarrollo prestaron también atención a las conexiones y al tipo de inserción exterior de los lugares. Si se actualiza esa idea, cabe recordar ahora que las iniciativas promovidas desde el ámbito local para enfrentar la crisis deben verse acompañados por la existencia de un entorno adecuado para alcanzar el éxito, pero que los procesos de dinamización inducidos desde el exterior encontrarán graves dificultades si no cuentan con la complicidad de los actores locales para su implementación.

Otro factor repetido en este tipo de aproximaciones al desarrollo fue la importancia de identificar y poner en valor toda una serie de recursos locales específicos -tanto materiales como inmateriales- resultado de un trabajo colectivo acumulado a lo largo de una trayectoria y generadores de diferenciación. Frente a las políticas de desarrollo desde arriba (top down), que proponen medidas homogéneas en todo su ámbito de actuación, estas propuestas de desarrollo desde abajo (bottom up) destacaron la importancia de utilizar estas capacidades localizadas como base en que cimentar las acciones a emprender, cuestionando la simple imitación de recetas de éxito en lugares con circunstancias a menudo bastante distintas.

Pero tal vez la idea más destacada y repetida en este tipo de literatura ha sido la creciente importancia otorgada a la innovación como componente necesario para impulsar el desarrollo local. No obstante, más allá de su omnipresente asociación al concepto de desarrollo, la propia definición de la innovación y la consiguiente caracterización de lo que cabe entender por territorio innovador están sometidas a importantes diferencias, lo que justifica precisar el significado que aquí se le da en relación con su utilización ahora como base de estrategias para superar la crisis. 
2.2. El discurso sobre el territorio innovador: de la innovación económica a la social

En un contexto dominado por la aceleración de los procesos y la creciente interdependencia espacial, el aumento de los riesgos y las incertidumbres derivadas para un elevado número de territorios se ha convertido ya en rasgo inherente a la nueva normalidad que define nuestro tiempo. Tal situación aumenta el valor de la anticipación y la prospectiva pero, sobre todo, de la adaptación a unos cambios rápidos y profundos, lo que equivale a reconocer la creciente importancia de la innovación y la creatividad como base necesaria, aunque no suficiente, para avanzar hacia un mayor y mejor desarrollo. La construcción y difusión de un discurso institucional sobre el valor de la innovación ha convertido en tópicas muchas de estas ideas, pero su traslación al territorio exige revisar algunas de las afirmaciones que se han convertido en lugar común en estos años, tal como propone la Figura 1.

De este modo, territorios innovadores serán aquellos donde se aplica una estrategia consciente y sistemática orientada a producir, transferir y aplicar un recurso estratégico como es el conocimiento en sus diversas formas (teórico o práctico, analítico, sintético o simbólico, explícito o tácito, etc.), acumulado

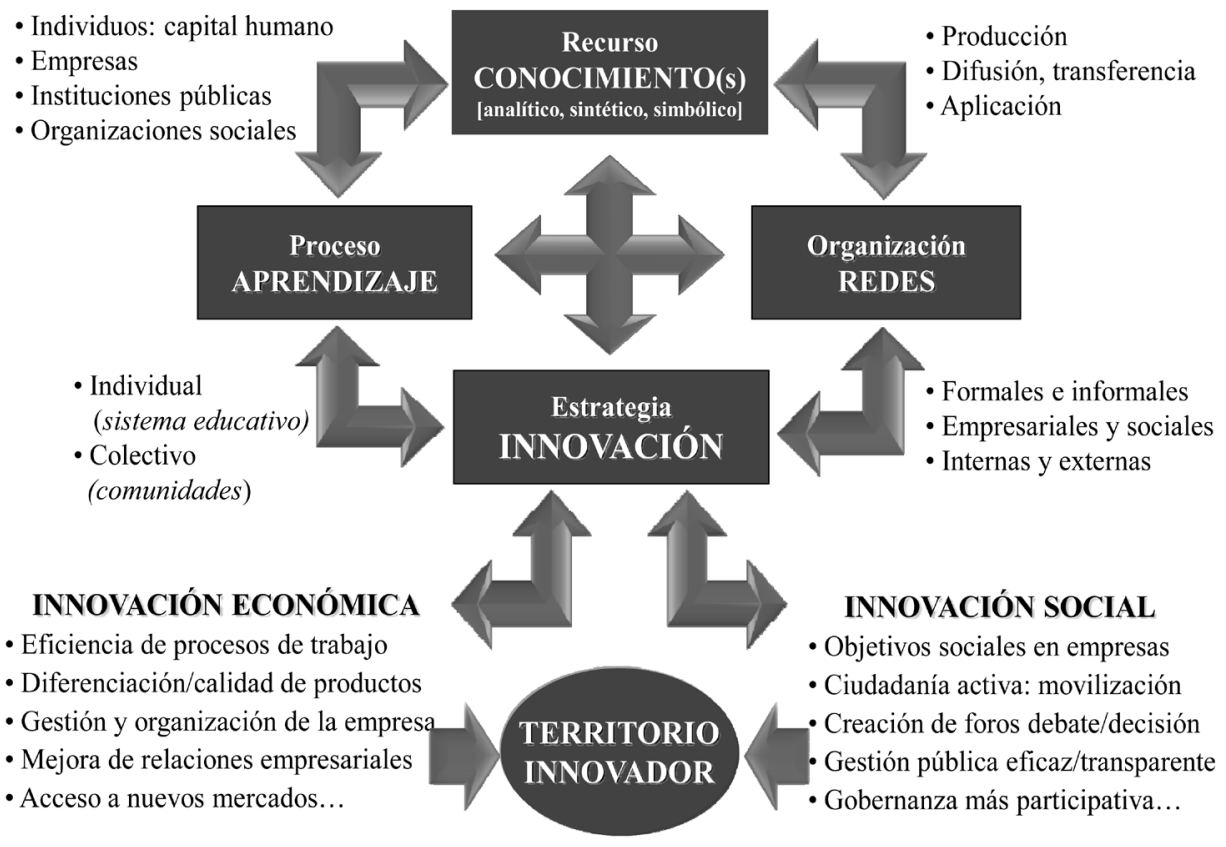

Fuente: Elaboración propia.

Figura 1. Territorios innovadores: principales factores y características. 
en su población, sus empresas, sus instituciones públicas y sus organizaciones sociales. Un primer objetivo, por tanto, será ampliar y activar su stock de capital cognitivo y de capital humano para favorecer un aumento de capacidades. Para ello será necesario promover procesos locales de aprendizaje, tanto individual -a través del sistema educativo y de una mejora en el nivel formativo de la población- como colectivo -a través del trabajo conjunto e interactivo que favorece la transmisión de conocimiento tácito, difícil de codificar- para lograr así un incremento de lo que algunos califican como inteligencia compartida.

Para impulsar esos procesos, la organización que resulta más eficaz es la construcción de redes, formalizadas o de carácter informal, entre actores locales con características, estrategias e intereses diferentes, pero comprometidos en objetivos comunes (CARAVACA y GONZÁLEZ, 2009). Pero, al mismo tiempo, en un mundo globalizado que se caracteriza por la densificación de todo tipo de flujos, cobran creciente importancia las relaciones multiescalares que desde los lugares se establecen con el exterior, tanto de sentido vertical como horizontal (VALE, 2011). El resultado de todo ello será la consolidación de procesos de innovación localizados, que hoy se consideran condición necesaria para el desarrollo local pero que, debido al uso abusivo del concepto, provocan cierta confusión sobre su verdadero significado.

Conviene recordar que la teoría de la innovación surgió en el ámbito de la economía y su traslación a los estudios territoriales tuvo lugar dentro de la geografía económica, que la consideró un objetivo estratégico para elevar la competitividad de aquellos territorios capaces de incorporarla a una proporción creciente de su tejido empresarial. Desde esta perspectiva inicial, una empresa innovadora $-y$, por extensión, una economía local innovadora- será aquella que incremente la eficacia de sus procesos de trabajo, junto a la calidad y diferenciación de los bienes o servicios producidos, mediante la incorporación de mejoras tecnológicas, así como en su organización y gestión internas, logrando también una apertura a mercados cada vez más amplios gracias a su creciente capacidad competitiva. Desde su origen, este tipo de estudios destacó que las mayores tasas de innovación se alcanzaban en aquellos lugares donde empresas próximas que trabajan en torno al mismo tipo de bienes o servicios mantienen estrechas relaciones de complementariedad y colaboración para lograr mayor eficiencia colectiva.

Pero existen territorios que, pese a poder calificarse incluso como polos científico-tecnológicos y contar con numerosas empresas innovadoras, no necesariamente traducen eso en un desarrollo más inclusivo para el conjunto de sus ciudadanos, más sostenible en el plano ambiental, o en una gestión pública más eficaz. Al mismo tiempo, "el éxito de una empresa no se relaciona sólo con el dinamismo del sector al que pertenece y con una superior capacidad interna de inventar nuevas soluciones", sino que "al lado de las relaciones económicas de producción asumen un papel esencial las relaciones sociales de cooperación y 
la compenetración de las empresas en las redes de relaciones socioeconómicas que constituyen el sistema local, entendido como integrador versátil de conocimientos y organización" (SFORZI, 1999: 28). De ahí la necesidad de convertir también a los territorios en ambientes socialmente innovadores si el objetivo es contribuir a un desarrollo más integrado del territorio.

El concepto de innovación social tiene ya un cierto recorrido aunque su incorporación a los estudios sobre desarrollo territorial sea bastante más reciente (FONTAN et al., 2004; MOULAERT y NUSSBAUMER, 2005; ANDRÉ y ABREU, 2006; KLEIN y HARRISON eds., 2007; MacCALLUM et al., 2009) y su utilización esté sujeta a significados diversos debido a su carácter multidimensional, lo que es origen de ciertas ambigüedades que recomiendan una breve justificación del sentido con que aquí se utiliza (MOULAERT et al., 2005).

Un primer uso, que resulta habitual en los estudios empresariales, suele vincularlo con la mejora de las relaciones sociales en el seno de las empresas para favorecer su innovación tecnológica y organizativa, el reforzamiento de su responsabilidad social y/o la promoción de un sector de economía social impulsado por motivaciones éticas más amplias que el beneficio o la competitividad. Una segunda acepción considera que la innovación social "consiste en elaborar respuestas nuevas a necesidades sociales también nuevas o mal satisfechas en las actuales condiciones del mercado y las políticas sociales, implicando la participación y cooperación de los actores afectados" (GÈZE dir., 2012: 6), lo que la vincula a la provisión de determinados bienes y servicios por parte de asociaciones, fundaciones, cooperativas, gobiernos locales, etc. Desde esta doble perspectiva, un territorio socialmente innovador será aquel donde las empresas e instituciones preocupadas por algunos de estos objetivos alcanzan cierta importancia relativa.

Pero el sentido con que aquí se utiliza el concepto es el que vincula la innovación social con la transformación de las relaciones y las prácticas sociales que caracterizan a un territorio determinado y que pueden favorecer un desarrollo más inclusivo y sostenible, así como una gobernanza más participativa y adaptada a las específicas condiciones y necesidades locales. Desde esta otra perspectiva, en un buen número de territorios puede considerarse socialmente innovador:

- promover una ciudadanía más activa, movilizada y organizada en defensa de mejores condiciones de vida y en la propuesta de nuevas alternativas de desarrollo

- crear o consolidar foros estables para la interacción y, de este modo, la acumulación de capital social, lo que incluye el debate, la negociación, la resolución de conflictos y la toma de decisiones relacionadas con el desarrollo local

- abrir estos ámbitos de participación a nuevos actores sociales, habitualmente poco representados, para establecer vías de comunicación por las 
que puedan expresas sus necesidades y, en su caso, reorientar la agenda local de prioridades

- avanzar hacia una gestión de los asuntos públicos más eficaz, accesible para los ciudadanos y transparente, lo que afectará de modo directo al funcionamiento de las administraciones locales.

Se establece así un evidente vínculo entre desarrollo local, innovación económica, innovación social y relaciones de gobernanza, pero el uso también múltiple que suele darse a este último concepto aconseja algunas precisiones al respecto.

De forma habitual, la gobernanza se define como un modo de regulación basado en la cooperación entre diferentes actores públicos y privados, que establecen acuerdos implícitos o explícitos, en la que los procesos de deliberación y decisión sobre cuestiones importantes se comparten, lo que conlleva cierto reparto de responsabilidades. En expresión de ASCHER (2004: 52), "la asociación de diferentes tipos de actores es una forma reflexiva de regulación, más adaptada a una sociedad abierta, muy diversa, móvil e inestable, que aporta una estabilidad relativa en un contexto marcado por todo tipo de incertidumbres". Presupone, en cierto modo, la existencia en el territorio de un capital social de reciprocidad (BAGNASCO et al., 2003) tejido por relaciones de confianza y activado de forma intencional por actores locales con intereses diversos, pero unidos por vínculos débiles en relación con valores compartidos y objetivos comunes que hacen referencia al desarrollo local.

Desde la perspectiva convencional en el análisis de la gobernanza, esa concertación entre actores múltiples (stakeholders) dota de mayores recursos y legitimidad a las acciones para el impulso de la innovación y el desarrollo local. El gobierno relacional, entendido así, "permite captar mejor el conocimiento relevante para tomar decisiones..., gestiona y equilibra mejor los intereses en liza..., confiere interlocución sistemática al capital social del territorio, lo que favorece las relaciones de confianza y reciprocidad..., es un espacio más proclive a la innovación que las estructuras burocráticas convencionales de carácter jerárquico y posibilita la movilización plural de recursos" (PASCUAL y GODÁS, 2010: 29). En consecuencia, cabe esperar que aquellos territorios donde el número de actores implicados sea mayor, más densas las relaciones que los interconectan y más numerosos los proyectos emprendidos, gozarán de ventajas comparativas.

No obstante, ese efecto positivo no parece en absoluto garantizado pues, a menudo, la gobernanza es más formal que real porque la existencia de relaciones de poder desequilibradas y la defensa de intereses contrapuestos entre los integrantes de las coaliciones locales pueden suponer un déficit democrático (SWYNGEDOUW, 2005). En unos casos se observa la existencia de redes locales que funcionan "a la sombra de la jerarquía” (JESSOP, 1997: 575), bajo el dominio de formas tradicionales de autoridad de carácter vertical, en donde 
la participación de los actores sociales se limita al asesoramiento o el debate para legitimar decisiones de gobierno. En otros el discurso se utiliza como justificación para externalizar ciertos segmentos de la gestión local desde el sector público al privado tal como postulan las tesis neoliberales, por lo que "el cambio de gobierno a gobernanza implica la influencia de nuevos actores en la toma de decisiones políticas, dado que las redes se amplían para incluir nuevas representaciones", lo que "detrae poder político del alcance de los representantes democráticamente elegidos" (PIKE et al., 2011: 200-201) en beneficio de determinadas élites.

Por lo tanto, no todas las formas de gobernanza favorecerán la puesta en marcha de estrategias de innovación orientadas al desarrollo en la misma medida, lo que obligará a analizar con cierto detenimiento en cada caso la estructura interna de las coaliciones locales.

\section{TERRITORIOS EN CRISIS: VULNERABILIDAD Y DESIGUALDAD ESPACIAL}

Pero si la innovación se considera importante para promover el desarrollo de todo tipo de regiones, ciudades o áreas rurales, alcanza un significado estratégico en momentos como los actuales, cuando un buen número de ellas se enfrenta a un declive que, entre otros efectos, viene a cuestionar las trayectorias de desarrollo seguidas durante las últimas décadas.

Conviene recordar que las crisis capitalistas son procesos periódicos e inherentes a la lógica del sistema, que se hacen más frecuentes e intensos en periodos en que se liberalizan los mercados hasta el punto de poder afirmarse que "el capitalismo no regulado es el peor enemigo de sí mismo", pues "más pronto o más tarde está abocado a ser presa de sus propios excesos" (JUDT, 2010: 18). En este caso, la crisis de unas finanzas internacionales que crecieron a un ritmo vertiginoso y de forma descontrolada en un ambiente progresivamente desregulado por la progresiva influencia del neoliberalismo, afectó de forma inmediata a la brusca detención del crecimiento económico ante las restricciones al crédito, tanto privado como público. Su efecto resultó particularmente intenso en países que, como España, conocieron en la década anterior el paralelo crecimiento de una burbuja inmobiliaria sin precedentes, apoyada no sólo por el crédito abundante y barato a las familias, sino también por una Ley del Suelo, una política fiscal y una relajación de la ordenación territorial acordes con los intereses del bloque hegemónico (NAREDO, 2009; LÓPEZ y RODRÍGUEZ, 2010; ROMERO et al., 2012). El rápido endeudamiento público derivado de la caída de ingresos, junto al tímido intento de poner en marcha políticas de reactivación, condujo a una respuesta en el seno de la Unión Europea que planteó como prioridad una austeridad fiscal de corte neoliberal que ha acentuado la recesión y el deterioro de la calidad de vida para la mayoría de los ciudadanos. 
Pero más allá de procesos bien conocidos y cuya interpretación en profundidad es ajena a nuestros objetivos, cualquier análisis, por superficial que resulte, confirma que el impacto de las crisis muestra intensidades y manifestaciones muy diferentes según territorios - cualquiera que sea la escalaconsiderada-, lo que exige una interpretación de ese diverso comportamiento. Por una parte, algunos se muestran particularmente frágiles y padecen un rápido deterioro de su situación, mientras otros parecen dotados de mayor resistencia y sus indicadores de desarrollo se han visto menos afectados. Por otra, algunos lugares consiguen adaptarse mejor al nuevo contexto, renovarse y recuperarse en un tiempo más o menos breve, en tanto otros inician un periodo de deterioro prolongado, sin encontrar alternativas para superar esa situación. Por último, mientras ciertos territorios se muestran incapaces de articular respuestas propias ante la crisis y cifran sus expectativas de reactivación tan sólo en la ayuda externa, otros logran poner en marcha respuestas proactivas y proyectos compartidos para hacerle frente, aunque sus resultados sean limitados y no siempre se hagan visibles de inmediato.

\subsection{Territorios resistentes, territorios vulnerables}

En consecuencia, cabe afirmar que la actual crisis tiene, sin duda, una dimensión global pues afecta de una u otra forma al sistema mundial en su conjunto, pero se gestó en lugares concretos - con los grandes centros financieros y las áreas de urbanización masiva en lugar destacado- y ofrece manifestaciones e intensidades muy heterogéneas, que profundizan las desigualdades espaciales a diferentes escalas. Constituye por tanto, según MARTIN (2011), un buen ejemplo de glocalización en el que los procesos estructurales se combinan con los efectos ejercidos por el específico marco regulatorio estatal y por las diferentes trayectorias y características locales para provocar esa heterogeneidad. En ese tipo de interpretación resultan de utilidad conceptos como los de vulnerabilidad y resiliencia territorial, utilizados en un argumento que se esquematiza en la Figura 2 y sobre el que puede hacerse un comentario que permita precisar dos conceptos de uso progresivamente frecuente en los estudios territoriales y sobre desarrollo, pero con significados múltiples que favorece cierta confusión.

El concepto de vulnerabilidad ha alcanzado especial desarrollo en el ámbito de los estudios ambientales y en relación con el análisis de desastres, pero en los últimos años se ha difundido también en las ciencias sociales. En tal sentido, puede considerarse vulnerable a aquella persona, grupo social, empresa o territorio con alta probabilidad de verse afectado por algún tipo de daño significativo en función de dos tipos de razones que a menudo se complementan. En primer lugar, una elevada exposición a riesgos de diversa naturaleza o a situaciones adversas que escapan a su control. Al mismo tiempo, su indefensión y escasa capacidad de respuesta por sus propias debilidades internas, que se acentuarán si se ven acompañadas por un escaso apoyo externo, incapaz de 
atenuar los daños provocados. Factores externos e internos suman, por tanto, sus efectos y provocan que todas las crisis acentúen las desigualdades a diferentes escalas, pues es "la tensión dialéctica entre ambos tipos de factores la que produce y reproduce un desarrollo geográfico desigual" (HADJIMICHALIS, 2011: 257).

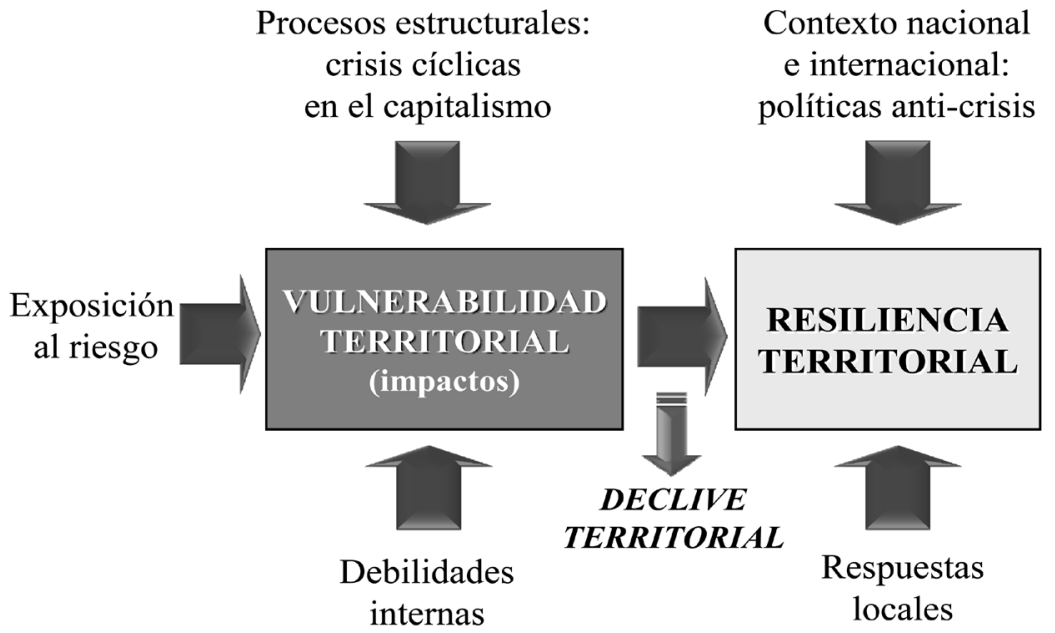

Figura 2. Crisis, vulnerabilidad y resiliencia de los territorios: una propuesta interpretativa.

Fuente: Elaboración propia.

A partir de esa situación, la evolución posterior del territorio puede suponer la profundización en un declive que se manifieste en indicadores económicos (estancamiento del PIB y la inversión, desaparición de empresas, caída del empleo y aumento del paro...), demográficos (saldo migratorio negativo, envejecimiento...), sociales (reducción de servicios públicos, aumento de desigualdades, de población en riesgo de pobreza y exclusión, patologías sociales...), inmobiliarios (depreciación del valor de las viviendas, desahucios...), paisajístico-ambientales (áreas residenciales y empresariales abandonadas, deterioro de infraestructuras...) y perceptivos (inmovilismo, asistencialismo, ausencia de proyecto de futuro...). Pero en otros casos, algunos territorios demuestran mayor capacidad para enfrentarse a esa situación y revertirla, lo que será más factible si en el ámbito nacional e internacional se adoptan políticas adecuadas para la recuperación, pero de nuevo exigirá también respuestas específicas en cada lugar, tal como ya plantearon los estudios sobre desarrollo local desde hace tiempo.

Si se centra ahora la atención en la vulnerabilidad territorial -pues de la resiliencia trata la última parte de la ponencia-, esta presenta algunos rasgos característicos, el primero de los cuales es su carácter relativo, pues todo espa- 
cio es, hasta cierto punto, vulnerable pero en distinto grado, por lo que la aplicación del concepto sólo tiene sentido en términos comparativos de mayor o menor vulnerabilidad. En segundo lugar, la vulnerabilidad es dinámica, pues a menudo la fragilidad actual es resultado de un largo proceso histórico y persiste en el tiempo, pero eso no conlleva ningún determinismo pues puede aumentar o disminuir en relación con decisiones y acciones tomadas por la sociedad y los actores locales en momentos determinados, capaces de quebrar el sentido de una trayectoria.

En ese sentido, la vulnerabilidad territorial debe entenderse como una construcción social, por lo que ideologías como la neoliberal, que favorece la competencia entre desiguales, erosiona los mecanismos de solidaridad y busca reducir la acción pública en materia de protección social, ordenación del territorio y establecimiento de controles a la acción de los mercados, aumentan la vulnerabilidad del territorio en su conjunto, pero en especial la de las áreas donde se localizan los grupos sociales o empresas con mayor dificultad para enfrentarse a esa competencia. También la de aquellos lugares que optaron por modelos de crecimiento excesivamente especializados en lo económico, polarizados en lo social e insostenibles en lo ambiental, más expuestos al riesgo aunque en ciertos periodos esa opción generase altas tasas de crecimiento.

Pero, más allá de esos rasgos básicos, queda por resolver cuáles pueden ser las características territoriales que aumentan la capacidad de resistencia y reducen la vulnerabilidad frente a una determinada crisis. En ese sentido, pueden apuntarse algunas ideas relacionadas con una bibliografía internacional bastante escasa hasta el momento, entre la que destaca por su mayor número la relacionada con los estudios urbanos (CLARK, 2009; SOTO, 2010; PERLÓ, 2011; MÉNDEZ, 2013).

\subsection{Claves explicativas de la diversa vulnerabilidad territorial frente a la cri- sis: un argumento en construcción}

Un primer factor esencial a considerar es la estructura económica heredada por el territorio. Resulta habitual interpretar que aquellos que cuentan con una base económica diversificada tienden a una mayor estabilidad y a un menor impacto de los ciclos económicos que los altamente especializados, pero entre estos últimos los comportamientos resultan muy heterogéneos según el tipo de especialización al inicio de la crisis. Hace ahora tres décadas, el agotamiento del modelo de producción fordista generó impactos de especial gravedad en ciudades mineras e industriales especializadas en sectores intensivos en recursos naturales o mano de obra, que se enfrentaron a la reconversión de su base productiva, con cierres de empresas, ajustes de capacidad, deslocalizaciones y una elevada destrucción de empleo que afectó al bienestar de su población. En el ámbito europeo, los efectos más negativos se concentraron en las regiones y 
ciudades de antigua tradición industrial del Arco Atlántico, sin excluir enclaves en otras áreas con un perfil de especialización socioeconómica similar.

Por el contrario, en la actual crisis la incidencia relativa de los diversos factores ya mencionados (financieros, inmobiliarios, regulatorios...) ha provocado efectos territoriales diferentes según países, regiones o ciudades, que también parecen haberse desplazado a lo largo del tiempo. Así, por ejemplo, la crisis iniciada en 2008 tuvo un reflejo inmediato en los principales centros financieros del Reino Unido (LEE, MORRIS \& JONES, 2009), mientras en Francia fueron las áreas industriales las más afectadas por la creciente dificultad para exportar y el freno de su demanda interna (DAVEZIES, 2012). Por su parte, en España el impacto se concentró en los territorios de la burbuja inmobiliaria, con el litoral mediterráneo, las islas y las periferias de las grandes metrópolis como las áreas más gravemente afectadas (FERNÁNDEZ TABALES y CRUZ, 2013). Pero, a partir de 2010, a esa primera fase de la crisis le ha seguido otra que se centra en los países de la periferia europea con un mayor desequilibrio de sus cuentas públicas y su sector financiero, que exigió una inyección de liquidez saldada con la imposición de una política de austeridad muy restrictiva que frena el consumo y afecta al conjunto de sus territorios, pero sobre todo a aquellos donde el empleo público en servicios sociales y las transferencias del Estado tenían mayor importancia relativa. Regiones periféricas, ciudades capitales o centros comarcales de servicios parecen ahora los principales perjudicados, aunque queda mucha investigación por hacer en este sentido para territorializar el impacto de esas medidas, que evidencian la influencia de los factores políticos en el mapa de la crisis que ahora se dibuja.

Otro posible factor explicativo a debate se refiere al efecto de protección frente a la crisis que ha supuesto contar con un importante volumen de actividades y empresas intensivas en conocimiento -cualquiera que sea su sector de actividad- un sistema regional de innovación bien articulado y con densas redes de relaciones exteriores, así como un elevado stock de capital humano con alto nivel formativo. Tanto las propuestas sobre territorios innovadores como sobre la sociedad del conocimiento dan por hecha esa correlación positiva, señalando que la pérdida de competitividad y la destrucción de empleo afectará en mayor medida a territorios con actividades de baja productividad, que no renuevan sus productos, sus procesos de trabajo o la organización y búsqueda de nuevos mercados por parte de sus empresas, o que cuentan con trabajadores poco cualificados, ya sea en servicios al consumo, construcción o industrias tradicionales. Algunos estudios (FLORIDA, 2011) apuntan en esa dirección, pero de nuevo en este caso faltan aún investigaciones que confirmen tales hipótesis en el caso europeo a partir de estudios locales más profundos que las simples correlaciones estadísticas.

Junto a la base económica, la eficacia de las políticas anti-crisis o la capacidad innovadora, no debe ignorarse la relación que vincula el sistema de 
relaciones laborales y la mayor estabilidad o precariedad en la contratación con el impacto que la reducción del crecimiento económico ejerce sobre el desempleo, una de las lacras más graves y con mayor capacidad de extender sus devastadores efectos sobre la sociedad y la economía locales. Resulta frecuente que los primeros afectados por la recesión sean los trabajadores en situación de precariedad laboral y que los territorios donde ésta es importante padezcan con mayor intensidad y rapidez sus efectos mediante un incremento de sus tasas de paro. Eso provoca también una mayor vulnerabilidad potencial de aquellas áreas donde se concentran los principales grupos de riesgo desde la perspectiva laboral (jóvenes, mujeres, inmigrantes, trabajadores sin cualificación y con bajos ingresos...), lo que favorece altos niveles de concentración espacial y la aparición de bolsas de desempleo de larga duración.

Finalmente, el estado de las finanzas públicas, el nivel de endeudamiento de los gobiernos autonómicos y locales, junto a la voluntad y capacidad de las administraciones para mantener su anterior nivel de inversión en ciertas partidas estratégicas o, por el contrario, su estricta aplicación de unas políticas de austeridad que ahogan las posibilidades de recuperación y acentúan la desigualdad socio-espacial también puede resultar un factor significativo de los contrastes que hoy se observan. Pero desde un planteamiento acorde con la idea de gobernanza, no debe ignorarse la influencia que sobre el desigual impacto de la crisis también ejercerá ahora la capacidad mostrada por el conjunto de actores locales para diagnosticar la situación, sus posibilidades e imposibilidades, así como los recursos específicos existentes, bases con las que plantear -una vez más en bastantes lugares que ya se enfrentaron a retos similares- un nuevo proyecto de futuro creíble y viable. La acumulación de capital institucional y relacional en el pasado reciente puede así favorecer cierta capacidad para renovar estrategias en momentos como los actuales, en que la escasez de recursos públicos y privados hace aún más necesaria la suma de esfuerzos. En esa perspectiva, el concepto de resiliencia territorial puede suponer la renovación de un discurso movilizador que, no obstante, guarda una evidente relación con la tradición de estudios y acciones sobre desarrollo local, lo que justificaría una reflexión que evite caer en una ingenua rendición ante las modas terminológicas, pero evite también el recelo generalizado ante cualquier novedad, antes de valorar sus potencialidades y limitaciones.

4. Estrategias LOCALES FRENTE A LA CRISIS: SIGNIFICADO DEL CONCEPTO DE RESILIENCIA TERRITORIAL

La actual crisis no corresponde a un desajuste transitorio de las finanzas internacionales tras el que cabe esperar la recuperación espontánea de un supuesto equilibrio anterior, sino que resulta ya patente la insostenibilidad de determinados modelos de crecimiento que están en el origen de lo ocurrido. Si se 
vuelve la vista hacia el pasado reciente, se confirma que frente a procesos de declive como los que provocó en determinadas regiones y ciudades la crisis del fordismo hace ya tres décadas, tan sólo algunas fueron capaces de adaptarse a los cambios, definir un nuevo proyecto de futuro y recuperar la senda del desarrollo, mientras otras entraron en una prolongada atonía en la que el escaso crecimiento económico, la fractura social y la esclerosis institucional han pervivido en el tiempo.

Se necesitan, por tanto, respuestas proactivas y no sólo defensivas frente a la crisis que exigirán decisiones y acciones a diferentes escalas. Por una parte, acuerdos en el plano internacional y, particularmente, en el de la Unión Europea, que pongan freno a los excesos de un hipercapitalismo de perfil neoliberal incapaz de autorregularse y que ahora prima el ajuste fiscal por encima del bienestar de sus ciudadanos o la creación de empleo. También políticas activas de los gobiernos centrales de esos Estados que ayuden a retomar la senda del crecimiento, reorientar el sistema productivo para hacerle más intensivo en conocimiento, recuperar cierta capacidad de apoyar actividades y empresas consideradas estratégicas, favorecer un empleo de mayor calidad o reducir una brecha social que atenta contra el principio de cohesión. Sólo un cambio en las relaciones de poder y el restablecimiento de un marco regulatorio que ponga límite a los abusos de estas últimas décadas y recupere el valor de la ordenación territorial generará un nuevo ambiente que haga posible la recuperación y un desarrollo más sostenible.

Pero, tal como también ocurrió en ese pasado no tan lejano, se necesitan igualmente estrategias locales que acompañen las adoptadas en instancias superiores, pues cada territorio deberá reconstruir su propia trayectoria y reinventarse en cierta medida para encontrar una salida tras la crisis. Lograr, en suma, un resurgimiento en el que "a un periodo de declive absoluto le sigue un cambio de tendencia y la consiguiente recuperación" (TUROK y MYKHNENKO, 2008: 56).

Cómo lograrlo debiera ser, por tanto, una pregunta central en este momento para los estudios territoriales, al menos en países de la periferia europea como el nuestro donde el impacto es más agudo, lo que supone un nuevo reto para quienes se interesan por el desarrollo local. En la búsqueda de respuestas basadas en la observación de cómo determinados territorios se enfrentaron a crisis precedentes puede resultar de utilidad una reflexión sobre el concepto de resiliencia, que ha comenzado a utilizarse en estos últimos años para interpretar procesos tanto a escala regional como urbana (PIKE, DAWLEY y TOMANEY, 2010; LANG, 2011; MARTIN, 2012). Sin hacer una revisión del origen, el trasvase interdisciplinar y los diversos significados de esta metáfora emergente, sometida al riesgo de la moda que puede favorecer su banalización y ser origen de cierta confusión respecto a su uso (HASSINK, 2010), merece la pena considerar su significado y, sobre todo, las posibles claves explicativas de las 
diferente capacidad de recuperación mostrada por territorios que se enfrentaron a situaciones de crisis derivadas de un acontecimiento externo, sintetizando ideas planteadas en un texto anterior (MÉNDEZ, 2012) para adecuarlas a los objetivos de esta ponencia.

\subsection{Precisar el concepto de resiliencia territorial}

En este sentido, la resiliencia territorial puede entenderse como la capacidad de adaptación positiva que muestran algunos lugares para enfrentar situaciones adversas generadoras de graves impactos, que resultan de crisis originadas por fenómenos o procesos externos, pero reforzados por ciertas debilidades endógenas que les hicieron especialmente vulnerables, para resurgir fortalecidos a partir de una estrategia de transformación interna. Si bien en algunos casos esas adversidades pueden corresponder a catástrofes puntuales debidas a causas naturales o de origen humano (ciclones, sismos, tsunamis, bombardeos...), son más frecuentes las derivadas de crisis sistémicas como la actual, que pusieron en cuestión las actividades y funciones en que se basó su crecimiento anterior, planteando graves incertidumbres sobre su viabilidad futura (POLĖSE, 2010). Otras definiciones procedentes de ámbitos donde el concepto ha tenido mayor desarrollo como son los estudios ambientales o la psicología clínica y social resultan coherentes con este planteamiento. Así, por ejemplo, la que asocia la resiliencia a "la capacidad de las comunidades para resistir shocks externos a su infraestructura social" (ADGER, 2000: 347), o la vincula a "una pauta de comportamiento y funcionamiento que indica una adaptación positiva en el contexto de un riesgo o adversidad significativos" (KEYES, 2004: 224).

La resiliencia corresponde, por tanto, a un proceso dinámico de trabajo consciente, destinado a lograr una mejor adaptación al nuevo contexto, con efectos que sólo se harán visibles a medio/largo plazo. Por tanto, mientras todos los territorios pueden ser vulnerables en mayor o menor medida, no todos serán necesariamente resilientes, pues no resulta una cualidad inherente a todos ellos o permanente, sino una construcción social. Para hacerse presente, el proceso debe partir de un diagnóstico realista sobre los impactos de la crisis, así como las debilidades y potencialidades del territorio para, a partir de ahí, poner en marcha la movilización de recursos y emprender acciones destinadas a superar inercias y bloqueos heredados que lastran su recuperación, aplicando estrategias de innovación económica y social que permitan encontrar nuevas respuestas. No se trata, por tanto, sólo de resistencia ni de pretender el regreso a modelos de crecimiento que se muestran ya agotados, pero tampoco de proponer objetivos quiméricos que ignoren sus posibilidades y limitaciones actuales, así como las derivadas de un entorno recesivo.

Si la resiliencia supone reiniciar la senda del desarrollo, los indicadores que pueden servir para identificar a aquellos lugares que han iniciado ese camino 
serán los mismos utilizados de forma habitual para valorar el desarrollo territorial. La reducción del impacto de la crisis sobre los grupos sociales, empresas y espacios más afectados, la recuperación del crecimiento de la actividad económica y del empleo, la recuperación y posterior elevación de los niveles de bienestar social y de los servicios públicos destinados a ese fin, junto a la aprobación de instrumentos de ordenación territorial que favorezcan una urbanización más sostenible serán algunos de los más evidentes.

La experiencia acumulada en estudios que han investigado los comportamientos individuales y colectivos de quienes hubieron de superar adversidades graves que cuestionaron su futuro demuestra que no existe una única vía para avanzar en el objetivo de ser resiliente, ni se trata de un logro que, una vez alcanzado, resulte duradero, ideas que también pueden trasladarse a la experiencia vinculada con los estudios sobre territorios en crisis. En consecuencia, cada uno de ellos deberá explorar entre alternativas posibles y mantener un esfuerzo de adaptación a entornos tan cambiantes como los actuales, buscando la concertación del mayor número posible de actores locales en torno a un proyecto colectivo que resulte movilizador, aspecto especialmente difícil cuando el desigual reparto de los costes de la crisis aumenta la desconfianza y los conflictos internos. Eso supone abandonar tentaciones asistencialistas y entender que la resiliencia territorial nunca podrá basarse tan sólo en la ayuda externa. Tampoco ignorar el pasado, sino aprender de lo ocurrido y reconstruir a partir de los propios recursos -apoyados en lo posible por otros externos- pero renunciando a la simple imitación de recetas de éxito en otros territorios.

Pero si definir con cierta precisión qué puede entenderse por resiliencia territorial -siempre dentro de la habitual pluralidad existente en las ciencias sociales- resulta un primer paso necesario para justificar el uso de este concepto, la pregunta esencial a responder será identificar por qué algunos territorios, enfrentados en un momento determinado a los efectos de una crisis, muestran mayor capacidad para ser resilientes que otros. Junto con esta, la segunda cuestión también importante para los objetivos de la ponencia será comprobar hasta qué punto la teorización elaborada en las últimas décadas para entender las claves del desarrollo local y la innovación territorial puede resultar ahora de utilidad para entender algunas de esas diferencias. Y, por último, qué tipo de acciones y de instrumentos pueden ayudar a poner en marcha una estrategia consciente de revitalización económica, regeneración social y reequilibrio territorial que permita superar el actual declive de numerosos lugares para hacerlos cada vez más resilientes. Ofrecer respuestas sólidas sólo será posible si aumentan los estudios locales planteados desde esta perspectiva, que en ningún caso supondrían una ruptura, sino una renovación, de una línea de investigación ya consolidada. 
4.2. Claves locales para la reactivación de territorios más innovadores y resilientes

La observación de territorios que en el pasado reciente fueron capaces de incrementar su esfuerzo innovador para superar el declive provocado por una crisis anterior es una base de reflexión interesante pues, aunque esas crisis tuvieron orígenes y características diferentes a la actual, pueden deducirse algunas enseñanzas útiles.

Respecto a los factores que pueden impulsar la capacidad de resiliencia de los territorios, la influencia de los enfoques evolucionistas y neoinstitucionales en esos estudios permite proponer tres tipos que se complementan entre sí: (i) la influencia de la trayectoria histórica, junto con los recursos e instituciones heredados; (ii) la capacidad de los actores locales para generar iniciativas innovadoras y construir redes de colaboración que aumenten la eficiencia colectiva; (iii) la definición de toda una batería de estrategias concertadas, innovadoras en lo económico y en lo social, destinadas a lograr tanto la revitalización de la actividad y el empleo como la regeneración social y ambiental (MÉNDEZ, 2012).

Los procesos sociales tienen un carácter evolutivo y, por tanto, las herencias del pasado pueden provocar inercias que cuestionan la racionalidad de determinadas acciones presentes, condicionadas por una acumulación de decisiones y acontecimientos cuya influencia permanece y esa path dependence debe tenerse en cuenta al considerar su diversa capacidad de resiliencia frente a la actual crisis. De este modo, cada territorio hereda un stock de recursos materiales e inmateriales diferente en volumen y calidad, que incluye su dotación en capital físico en forma de infraestructuras y equipamientos, de capital productivo en forma de empresas, de capital financiero para invertir o de capital humano con cierto nivel formativo y de cualificación, que serán otras tantas bases para impulsar la recuperación.

Pero no debe olvidarse la importancia de un capital institucional que incluye los valores y comportamientos colectivos, normas u organizaciones, junto a unos estilos de gobierno y gestión de los asuntos públicos que pueden impulsar o frenar la búsqueda de nuevas soluciones. Transformar, por ejemplo, una cultura local en donde las decisiones estratégicas se tomaban tradicionalmente por el gobierno o por unos pocos actores en favor de otra más participativa, o hacer evolucionar un ambiente conflictivo de intereses encontrados y fuerte individualismo por otro de confianza y de colaboración ante la adversidad colectiva puede exigir tanto esfuerzo para acumular capital social que se traduzca en cauces de diálogo como la inversión en infraestructuras, educación, vivienda o desarrollo tecnológico.

Un segundo punto de encuentro entre los territorios que en el pasado afrontaron con relativo éxito una crisis es la presencia de individuos y organizaciones -tanto en el ámbito de las empresas, el sector público o la sociedad 
civil- con voluntad y capacidad para generar iniciativas que pueden calificarse de innovadoras, destinadas a recuperar su competitividad, pero también la calidad de vida de sus habitantes, sin limitarse a plantear respuestas defensivas o mantener un discurso asistencialista que espere soluciones procedentes tan sólo del exterior. Esos actores locales serán protagonistas necesarios de cualquier estrategia de dinamización que pueda emprenderse, pero también pueden suponer su principal obstáculo cuando su falta de iniciativa, de recursos (financieros, de conocimiento, relacionales...), o la defensa de intereses privados de determinadas élites en contradicción con los colectivos acaban por imponerse, frenando la recuperación o sesgando sus beneficios hacia unos pocos.

En ese sentido, dentro de la diversa geometría que pueden presentar las coaliciones locales de actores, no resultará banal la existencia de un liderazgo ejercido por el gobierno local, basado en cierto grado de credibilidad, confianza y autoridad, importante desde dos perspectivas complementarias. Por una parte, en la definición de objetivos colectivos orientados a promover la innovación, compatibles con los de la mayoría de grupos sociales y corporativos presentes en el territorio, aportando recursos financieros para su materialización. Por otra, como agente catalizador capaz de dialogar y tejer vínculos de confianza entre los restantes actores -tanto internos como externos- para promover foros de concertación, debate y, en su caso, negociación de las posibles alternativas de superación de la crisis, ya sea en el marco de un plan estratégico, un plan de reactivación, un pacto local, etc. (SALOM y ALBERTOS eds., 2009). Esa función de intermediación resulta aún más esencial en tiempos en que los recursos de las haciendas locales escasean y debe alertar sobre el riesgo que en la actualidad puede suponer una reforma de la Ley de Bases de Régimen Local que limite la capacidad de acción de los gobiernos de proximidad, lo que no impide recordar también los excesos cometidos en el pasado reciente desde estas instancias y su frecuente implicación en el crecimiento de la burbuja inmobiliaria (BURRIEL, 2011).

Respecto a las estrategias destinadas de forma explícita a promover la resiliencia, se trata, ante todo, de poner en marcha acciones a corto plazo destinadas a atender situaciones de urgencia social derivadas de la crisis, que exigen revertir el actual adelgazamiento del Estado de Bienestar. Programas de obra pública y de rehabilitación de vivienda para generar empleo, apoyo a PYMEs y autónomos, planes de formación ocupacional y de fomento de la economía social, freno a los desahucios y alquiler social de vivienda, aumento de la oferta asistencial a personas en riesgo de exclusión, etc., son algunos de los más repetidos y las acciones de proximidad son fundamentales en este sentido. Pero se necesita, sobre todo, poner en práctica actuaciones a medio y largo plazo que potencien la innovación económica, tanto en el seno de las empresas individuales como en la economía local en su conjunto, al tiempo que también favorezcan la innovación social, para reorientar así determinados 
modelos de crecimiento que se demuestran agotados e impulsar un verdadero desarrollo (Figura 3).

En el plano de la actividad económica, siempre importante pero crucial en momentos como los actuales en donde el objetivo de generar empleo e ingresos para la población resulta particularmente acuciante, pueden diferenciarse las acciones destinadas a promover el emprendimiento y reforzar la dotación en recursos para la innovación empresarial (soft policies) de aquellas orientadas a la construcción o rehabilitación de espacios para albergar empresas innovadoras que potencien una economía local más creativa (hard policies) y de las que buscan mejorar la eficiencia colectiva mediante el tejido de redes empresariales (network policies).

Entre las primeras, el difícil nacimiento de iniciativas emprendedoras que provoca toda crisis, tanto por la escasez de crédito como por la retracción de la demanda, hace más necesario aún el apoyo a las nuevas empresas, tanto en el terreno del asesoramiento como del apoyo financiero, comenzando en la fase previa a su nacimiento para continuar durante las primeras fases de su ciclo de vida. El fomento de una formación complementaria a la dependiente de instancias no locales, que busque una mejor conexión entre esa oferta y las demandas específicas del mercado local de trabajo, o el apoyo a la difusión

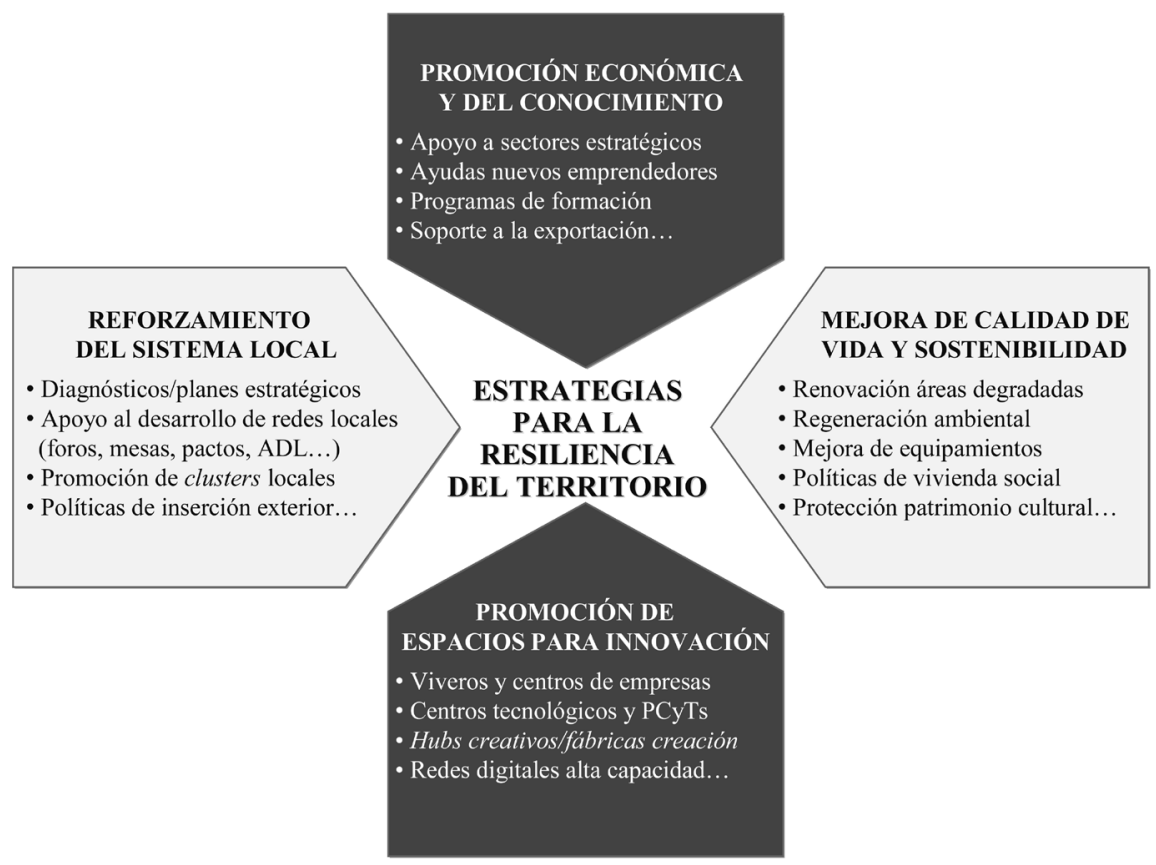

Figura 3. Estrategias locales frente a la crisis y para la resiliencia territorial.

Fuente: Elaboración propia. 
de los productos y servicios locales son acciones que no por conocidas dejan de seguir siendo importantes en momentos como los actuales. Por su parte, la tipología de espacios destinados a reunir empresas innovadoras e instituciones ligadas al conocimiento es amplia y bien conocida, abarcando también desde los viveros para favorecer el nacimiento de iniciativas creativas al apoyo técnico que pueden ofrecer los centros tecnológicos en fases más avanzadas de su ciclo de vida, la posibilidad de implantación en entornos de calidad donde se genera y se transfiere la I+D+i como deberían ser los parques científicos y tecnológicos, etc. Menos tradición tiene la construcción o rehabilitación de inmuebles para albergar industrias culturales y servicios creativos (edición, audiovisual, multimedia, software, diseño...), cuya capacidad para promover empleos cualificados y regenerar espacios urbanos ha sido objeto de creciente atención en los últimos años (WINDEN, 2011), no exenta de críticas por los efectos de segregación social y expulsión de antiguos residentes que a veces conlleva (MUSTERD, 2006).

Por el lado de la innovación social, la crisis pone en evidencia la importancia de la acción colectiva para resistir, pero también para responder con nuevos proyectos, el progresivo deterioro de la situación. Se revaloriza así la importancia de crear o -si ya existen- consolidar foros estables donde los diferentes actores urbanos puedan debatir y decidir acciones, incluidos aquellos movimientos ciudadanos que representan a grupos desfavorecidos o especialmente afectados por la crisis. En esa misma lógica de construir redes, el impulso a la formación de clusters locales (en la industria, el comercio, el turismo...) que desarrollen proyectos en común, en colaboración con actores políticos y sociales, puede entenderse que va más allá del ámbito estrictamente económico. Por último, las estrategias destinadas a mejorar el entorno, especialmente en aquellas áreas más castigadas por la crisis, así como a asociar la identidad y la imagen del territorio a valores como la calidad, la diversidad cultural, la protección del patrimonio, la dotación en bienes y espacios públicos o la tolerancia, serán útiles para renovar la imagen y la percepción de los propios ciudadanos respecto a la posibilidad de construir un proyecto de futuro más inclusivo y equilibrado

No obstante, tal como recuerda Felber en su defensa de una economía del bien común, "sería muy ingenuo por nuestra parte actuar como si este nuevo orden pudiera salir a escena sin un cambio en las relaciones de poder actuales" (FELBER, 2012:26). La resiliencia territorial tiene, por tanto, una dimensión política que aquí ha sido abordada tan sólo de forma tangencial, pero que no por ello debe ser ignorada. Dicen Forés y Grané en relación con la resiliencia que "el relato de nuestra historia nos remite al pasado para explicar el presente, pero nunca cierra el futuro" (FORÉS y GRANÉ, 2008: 19), afirmación interesante para ahuyentar discursos deterministas y ese pensamiento único autojustificativo ante la supuesta inexistencia de otras alternativas posibles. Pero de no 
modificarse el dominio de la ideología neoliberal y el poder de las coaliciones hegemónicas que condujeron a la situación presente, difícilmente tales posibilidades llegarán a convertirse en realidad y el trabajo desde los ámbitos locales seguirá siendo esencial para avanzar en esa dirección.

\section{Conclusiones}

Sin pretender un resumen de las diferentes cuestiones abordadas en la ponencia, parece conveniente finalizar planteando, al menos, el sentido que se pretendió dar al recorrido seguido, que comenzó con el recordatorio de algunas aportaciones esenciales de la literatura sobre desarrollo local que renuevan ahora su vigencia, para continuar considerando el reforzamiento de los contrastes entre territorios que surge de la actual crisis y finalizar con una propuesta de estrategias para la resiliencia territorial que pretenden ser coherentes con las aportaciones que desde el nuevo institucionalismo o el evolucionismo se han realizado en estos últimos años.

Los estudios geográficos y, en concreto, los relativos al desarrollo no pueden permanecer ajenos a la preocupación social que suscita hoy una crisis que puede entenderse como sistémica, tanto porque refleja las contradicciones del modelo de globalización neoliberal dominada por el capital financiero imperante en las tres últimas décadas, como porque sus efectos desbordan el plano estrictamente económico para alcanzar dimensiones sociales, políticas y también territoriales. En este último aspecto se ha afirmado que la crisis es un ejemplo de glocalización, pues aunque su dimensión es global existen múltiples geografías locales de la misma. Se necesita, por tanto, mucho mayor conocimiento sobre sus desiguales impactos como punto de partida para abordar la propuesta de alternativas mejor argumentadas y más adaptadas a las específicas condiciones locales.

Cada territorio es heredero de una trayectoria y son numerosos los que -agotado un modelo de crecimiento que se ha demostrado insostenible- deben enfrentarse ahora a la búsqueda de nuevos caminos para su desarrollo en un entorno cambiante y caracterizado por numerosas incertidumbres. Los estudios sobre desarrollo local y sobre ambientes innovadores surgieron en momentos específicos y como respuesta a necesidades concretas, pero desde la perspectiva que plantea la actual crisis pueden entenderse como convergentes en el objetivo de comprender mejor la diversa vulnerabilidad frente a la recesión económica $\mathrm{y}$, sobre todo, de alimentar estrategias de resiliencia que permitan alcanzar la revitalización de sus economías al tiempo que la regeneración de su tejido social. Aunque la gravedad de la situación exige en muchos casos abordar actuaciones de urgencia a corto plazo para atender a los sectores más desprotegidos, la principal necesidad sigue siendo plantear un programa a medio y largo plazo que redefina el horizonte hacia el que se pretende avanzar y que dote de sentido a las herramientas concretas que se pongan a su disposición. 
Desde la perspectiva del desarrollo territorial, la innovación no puede limitarse a considerar la capacidad científico-técnica o el potencial de las empresas locales para hacer más eficientes sus procesos y su organización, mejores sus productos o sus formas de acceso a nuevos mercados. Junto a estas dimensiones de la innovación económica, sin duda importantes, la capacidad de resiliencia exigirá considerar también el fomento de la innovación social, renovando comportamientos y formas de organización para lograr mejoras tangibles en aspectos tan diversos la calidad de vida, la participación ciudadana, la protección del patrimonio y el paisaje, o la sostenibilidad ambiental.

Aunque no existe una única vía para promover un mayor esfuerzo innovador que conduzca a un mejor desarrollo y, en la situación presente, a la recuperación de áreas en declive, sí pueden proponerse ciertos criterios comunes extraídos de experiencias anteriores y que deberán someterse a debate y, en su caso, renovación. Construir (o reconstruir) en esos territorios una gobernanza relacional entre diferentes actores que mantenga el liderazgo del gobierno local como promotor de iniciativas e intermediador, evitando la posible usurpación de la representación ciudadana por determinadas élites, supone una base de partida. Plantear alternativas que tomen en consideración la trayectoria previa y los recursos disponibles para evitar saltos en el vacío o la simple imitación de estrategias aplicadas con éxito en otros lugares resulta otra idea a considerar. Construir relaciones de colaboración más densas para proyectos concretos cuyos resultados permitan acumular capital social, al tiempo que no se descuida una buena inserción exterior es un tercer elemento necesario para actuar en un mundo de redes como el actual.

No obstante, conviene evitar la ingenua suposición de que todo lo posible es igualmente probable, ignorando la lógica subyacente a los comportamientos que permitieron llegar a la situación presente. Abordar, por tanto, propuestas a favor de un nuevo desarrollo local exige una revisión crítica de ese contexto, pues sin una transformación en profundidad de algunos condicionantes resultará imposible lograr avances significativos. Será necesaria la sustitución de una agenda neoliberal que, con su interesada suposición sobre la racionalidad de los mercados y la primacía otorgada a enfoques monetaristas y de ajuste fiscal sobre la generación de crecimiento, empleo y bienestar, llevó al descontrol financiero e inmobiliario primero y a políticas de austeridad después que profundizaron la recesión. Será necesario también un cambio en las relaciones de poder que permita hacer oir su voz y participar en la toma de decisiones estratégicas a nuevos actores sociales organizados, diferentes a los que configuraron en el pasado reciente un bloque hegemónico poco interesado en un desarrollo más sostenible. Será conveniente también evitar traducir las simplistas recetas de la austeridad en la pérdida de recursos y competencias para unos gobiernos de proximidad que deben hacer más eficaz y transparente su funcionamiento, pero que siguen siendo esenciales en la promoción del desarrollo local. Será 
indispensable, por último, una nueva cultura del territorio que reconozca su valor patrimonial y la necesidad de una ordenación que preserve determinados recursos para el presente y el futuro.

En definitiva, vivimos una situación que enfrenta a numerosos territorios, tanto en España como en otros países de la periferia europea, con importantes riesgos de fractura y eso refuerza la necesidad de explorar nuevos caminos que permitan superar el pesimismo y la inacción, La teoría y la práctica del desarrollo local aporta un bagaje de experiencias que puede resultar útil para conocer y comprender mejor cómo y por qué algunos lugares han sido capaces en su pasado reciente de lograr formas de desarrollo más equilibradas, justas y sostenibles que otros. La construcción de territorios resilientes -o cualquier otro calificativo que se aplique a los que fueron capaces de reactivarse tras la crisis- es en la actualidad un objetivo esencial para los estudios sobre desarrollo y, en consecuencia, sería deseable que los geógrafos reflexionasen de forma colectiva sobre su compromiso y capacidad para hacer frente a un reto tan relevante como este, tanto desde el punto de vista científico como social.

BiBLIOGRAFÍA

ADGER, W.N. (2000): "Social and ecological resilience: are they related?" Progress in Human Geography, no 24, p. 347-364.

ANDRÉ, I. y ABREU, A. (2006): "Dimensões e espaços da inovação social". Finisterra, vol. XLI (81), p. 121-141.

ASCHER, F. (2004): Los nuevos principios del urbanismo. Madrid, Alianza Editorial.

BAGNASCO, A.; PISELLI, F.; PIZZORNO, A. y TRIGILIA, C. (2003): El capital social: instrucciones de uso. Buenos Aires, Fondo de Cultura Económica.

BATHELT, H.; MALMBERG, A. y MASKELL, P. (2004): "Clusters and knowledge: Local buzz, global pipelines and the process of knowledge creation”. Progress in Human Geography, vol. 28 (1), p. 31-56.

BOISIER, S. (2013): "El humanismo en una interpretación contemporánea del desarrollo". Desenvolvimento Regional em Debate, Universidade do Contestado, vol. 3, $\mathrm{n}^{\mathrm{o}}$ 1, p. 4-22.

BURRIEL, E. (2011): "Subversion of land-use plans and the housing bubble in Spain“. Urban Research \& Practice, vol. 4, n 3, pp. 232-249.

CARAVACA, I. y GONZÁLEZ, G. (2009): "Las redes de colaboración como base del desarrollo territorial". Scripta Nova, vol. XIII, 289, [1 mayo 2009].

CLARK, G. (2009): Recession, recovery and reinvestment: the role of the local leadership in a global crisis. París, OCDE.

COMISIÓN EUROPEA (2010): Europa 2020. Una estrategia para un crecimiento inteligente, sostenible e integrador. Bruselas, Comisión Europea. 
DAVEZIES, L. (2012): La crise qui vient. La nouvelle fracture territoriale. París, Éditions du Seuil.

FELBERG, C. (2012): La economía del bien común. Barcelona, Deusto Ediciones.

FERNÁNDEZ TABALES, A. y CRUZ, E. (2013): Sector de la construcción y desarrollo territorial en Andalucía. Sevilla, Publicaciones de la Universidad de Sevilla.

FLORIDA, R. (2011): El gran reset .Nuevas formas de vivir y trabajar para impulsar la prosperidad. Barcelona, Paidós.

FONTAN, J.M.; KLEIN, J.L. y TREMBLAY, D.G. (2004): "Innovation et société : pour élargir l'analyse des effets territoriaux de l'innovation". Géographie, Économie, Société, no 6, p. 115-128.

FORÉS, A. y GRANÉ, J. (2010): La resiliencia. Crecer desde la adversidad. Barcelona, Plataforma Editorial, $2^{a}$ edición.

GÈZE, P. dir. (2012): L'innovation sociale, un levier pour le développement des territoires. París, Association des Règions de France-Avise.

GUMUCHIAN, H.; GRASSET, E.; LAJARGE, R. y ROUX, E. (2003): Les acteurs, ces oubliés du territoire. París, Anthropos.

HADJIMICHALIS, C. (2011): "Uneven geographical development and sociospatial justice and solidarity: European regions after 2009 financial crisis". European Urban and Regional Studies, vol. 18(3), p. 54-274.

HARVEY, D. (2007): Espacios del capital. Hacia una geografía crítica. Madrid, Akal.

HASSINK, R. (2010): "Regional resilience: a promising concept to explain differences in regional economic adaptability?" Cambridge Journal of Regions, Economy and Society, n ${ }^{\circ} 3$, p. 45-58.

JESSOP, B. (1997): "Capitalism and its future: remarks on regulation, government and governance". Review of International Political Economy, vol. $4, n^{\circ} 3$, p. $561-581$.

JUDT, T. (2010): Algo va mal. Madrid, Taurus.

KEYES, C.L.M. (2004): "Risk and resilience in human development: an introduction". Research in Human Development, vol. I, no 4, p. 223-227.

KLEIN, J.L. y HARRISON, D. (eds.) (2007): L'innovation sociale. Émergence et effets sur la transformation des societés. Quebec, Presses de l'Université du Québec.

LANG, T. (2011): "Urban resilience and new institutional theory. A happy couple for urban and regional studies?", en B.MÜLLER (ed.). Urban regional resilience: how do cities and regions deal with change? BerlínHeidelberg: Springer Verlag, p. 15-24.

LEE N.; MORRIS, K. y JONES, A. (2009): How UK cities can respond and drive the recovery. Londres, The Work Foundation, LEED Programme. 
LÓPEZ, I. y RODRÍGUEZ, E. (2010): Fin de ciclo. Financiarización, territorio y sociedad de propietarios en la onda larga del capitalismo hispano (19592010). Madrid, Traficantes de Sueños.

MacCALLUM, D.; MOULAERT, F. y HILLIER, F. (2009): Social innovation and territorial development. Londres, Ashgate.

MARTIN, R. (2011): "The local geographies of the financial crisis: from the housing bubble to economic recession and beyond". Journal of Economic Geography, vol. 11(4), p. 587-618.

MARTIN, R. (2012): "Regional economic resilience, hysteresis and recessionary shocks". Journal of Economic Geography, vol. 12(1), p. 1-32.

MÉNDEZ, R. (2012): "Ciudades y metáforas: sobre el concepto de resiliencia urbana”. Ciudad y Territorio Estudios Territoriales, vol. XLIV, n ${ }^{\circ}$ 172, p. 215-231.

MÉNDEZ, R. (2013): "Las escalas de la crisis. Ciudades y desempleo en España”. Madrid, Fundación $1^{\circ}$ de Mayo, Colección Estudios, n 60, http:// www.1mayo.ccoo.es/nova/ files/1018/Estudio60.pdf.

MOULAERT, F.; MARTINELLI, F.; SWYNGEDOUW, E. y GONZÁLEZ, S. (2005): "Towards alternative model(s) of local innovation". Urban Studies, vol. 42, no 11, p. 1969-1990.

MOULAERT, F. y NUSSBAUMER, J. (2005): The social region. Beyond the territorial dynamics of the learning economy. European Urban and Regional Studies, vol. 12, no 1, p. 45-64.

MOULAERT, F. y SEKIA, F. (2003): 'Territorial innovation models: a critical survey'. Regional Studies, vol. 37(3), p. 289-302.

MUSTERD, S. (2006): "Segregation, urban space and the resurgent city". Urban Studies, no 43, p. 1325-1340.

NAREDO, J.M. (2009): "La cara oculta de la crisis. El fin del boom inmobiliario y sus consecuencias". Revista de Economía Crítica, no 7, p. 313-340.

PASCUAL, J.M y GODÁS, X. (coords.) (2010): El buen gobierno 2.0: la gobernanza democrática territorial. Valencia, Tirant lo Blanch.

PERLÓ, M. (2011): "Cities in times of crisis. The response of local governments in light to the global economic crisis: the role of the formation of human capital, urban innovation and strategic planning". IURD Working Papers, Berkeley Institute of Urban and Regional Development, n 2011-01.

PICHIERRI, A. (2002): "Concertation and local development". International Journal of Urban and Regional Research, vol. 26(4), p. 689-706.

PIKE, A.; DAWLEY, S. y TOMANEY, J. (2010): "Resilience, adaptation and adaptability". Cambridge Journal of Regions, Economy and Society, n 3, p. 59-70.

PIKE, A.; RODRÍGUEZ-POSE, A. y TOMANEY, J. (2011): Desarrollo local y regional. Valencia, Ediciones Universidad de Valencia. 
POLÈSE, M. (2010): "The resilient city: on the determinants of successful urban economies". Working Paper n 2010-03, Centre-Urbanisation Culture Société. INRS. University of Quebec, Montrèal, p. 1-24.

ROMERO, J.; JIMÉNEZ, F. y VILLORIA, M. (2012): “(Un)sustainable territories: causes of the speculative bubble in Spain (1996-2010) and its territorial, environmental and sociopolitical consequences". Environment and Planning C, $\mathrm{n}^{\mathrm{o}} 30$, p. 467-486.

SALOM, J. y ALBERTOS, J.M. eds. (2009): Redes socioinstitucionales, estrategias de innovación y desarrollo territorial en España. Valencia, Publicaciones de la Universidad de Valencia.

SFORZI, F. (1999): La teoría marshalliana para explicar el desarrollo local, en F.RODRÍGUEZ (edit.) Manual de desarrollo local. Oviedo, Trea Ediciones, p. 13-32.

SOTO, P. (2010): Cities at the economic crisis. A survey on the impact of the economic crisis and the responses of URBACT II cities. Bruselas, Comisión Europea.

STÖHR, W. (1990): Global change and local response. Londres, Mansell.

SWYNGEDOUW, E. (2005): "Governance innovation and the citizen: the Janus face of governance-beyond-the-State". Urban Studies, vol. 42, n 11 , p. 1991-2006.

TUROK, I. y MYKHNENKO, V. (2008): "Resurgent european cities?" Urban Research\& Practice, vol. 1(1), p. 54-77.

VALE, M. (2011): "Innovation networks and local and regional development policy" en A.PIKE, A.RODRÍGUEZ-POSE y J.TOMANEY (eds.). Handbook of local and regional development. Nueva York, Routledge, p. 413-424.

VÁZQUEZ BARQUERO, A. (1999): Desarrollo, redes e innovación. Lecciones sobre desarrollo endógeno. Madrid, Pirámide.

VÁZQUEZ BARQUERO, A. (2005): Las nuevas fuerzas del desarrollo. Barcelona, Antoni Bosch.

WINDEN, W. van (2011): Creating knowledge hotspots in the city: a handbook. Bruselas, Comisión Europea, URBACT II-REDIS. 